\title{
PUSAT INDUSTRI FASHION BATIK DAN SASIRANGAN KHAS TABALONG
}

\author{
Elyda Zaiyantina Puteri \\ Program Studi Teknik Arsitektur Fakultas Teknik Universitas Lambung Mangkurat \\ rifqiel.ez@gmail.com

\section{Nurfansyah} \\ Program Studi Teknik Arsitektur Fakultas Teknik Universitas Lambung Mangkurat \\ nfsarsitek@ulm.ac.id
}

\begin{abstract}
ABSTRAK
Perancangan Pusat Industri Fashion Batik dan Sasirangan Khas Tabalong ini dilatarbelakangi oleh keinginan pemerintah untuk lebih memperkenalkan kain khas dari Kabupaten Tabalong. Keinginan ini menjadikan potensi untuk mengembangkan sebuah Pusat Industri Fashion yang berfokus pada pembatik dan pengunjung. Tujuan dari perancangan ini adalah mendapatkan desain yang membuat pembatik dapat meningkatkan kreativitas dan inovasi dalam membuat motif kain Batik dan Sasirangan serta produk fashion dan pengunjung dapat merasakan pengalaman. Dengan menerapkan konsep Cultural to Creativity yang dipadukan dengan konsep kreativitas 4P dan menggunakan metode Architectural Programming. Penerapan konsep budaya terdapat pada bentuk dan finishing eksterior bangunan, penerapan konsep kreativitas diterapkan pada sirkulasi, tata massa, dan interior.

Kata kunci: Batik dan Sasirangan khas Tabalong, Pusat Industri Fashion.
\end{abstract}

\section{ABSTRACT}

The design of Fashion Industry Batik and Sasirangan Tabalong Center was motivated by the government's desire to introduce more typical fabrics from Tabalong Regency. This desire makes the potential to develop a Fashion Industry Center that focuses on batik makers and visitors. The purpose of this design is to get a design that makes batik can increase creativity and innovation in making Batik and Sasirangan fabric motifs and fashion products and visitors can experience. By applying the Cultural to Creativity concept combined with $4 P$ creativity concepts and using Architectural Programming methods. The application of cultural concepts is in the shape and exterior finishing of buildings, the application of the concept of creativity is applied to circulation, mass management, and interior.

Keywords: atik and Sasirangan Tabalong, Fashion Industry Center, Cultural to Creativity.

\section{PENDAHULUAN}

Di setiap daerah di Indonesia, batik dapat dijumpai dengan mudah, karena batik merupakan warisan budaya asli bangsa ini.
Setiap daerah rata-rata memiliki batik dengan motif sendiri yang menjadi khasnya masing-masing, termasuk juga di Kabupaten Tabalong, daerah paling utara Kalimantan 
Selatan ini sudah ada memiliki batik khas yang dinamai Batik Tanjung Bersinar.

Pemerintah Kabupaten Tabalong meluncurkan batik khas bermotif ikon kebanggaan, yaitu buah langsat. Namun motifnya tidak hanya itu saja, melainkan juga beberapa motif ornamen suku Dayak. Dengan berbagai ornamen itu menunjukkan adanya kebersamaan di tengah kemajemukan masyarakat Tabalong, karena terdapat berbagai suku bangsa di dalamnya, khususnya suku Dayak dan suku Banjar. Motif Sasirangan diambil karena merupakan ciri khas Banjar, kemudian buah langsat dijadikan motif karena salah satu khas Tabalong. Sedangkan motif Dayak juga dimasukkan menjadi corak karena Dayak berjasa besar sehingga Tabalong bisa menjadi sebuah kabupaten, kemudian juga ada yang memvariasikan dengan motif lain, misalnya monumen Tanjung Puri atau yang dikenal dengan Tugu Obor (kalimantan post).

Bupati Tabalong $\mathrm{H}$. Anang Syakhfiani langsung yang meluncurkan batik itu, ia berharap kain baju dengan berbagai corak yang menyamai kain sasirangan ini bisa menjadi kebanggaan warga setempat, serta bisa dipromosikan ke daerah lain. Agar batik bisa terus dikenal dan terpromosikan di tengah-tengah masyarakat luas, Anang bertekad ke depan akan mewajibkan seluruh pegawai negeri sipil (PNS) mengenakannya di kegiatan-kegiatan resmi. Baik saat bekerja maupun di luar jam kerja. "Kami meluncurkan batik Tabalong bersinar yang pada saat ini kami dan bapak ibu kenakan. Batik ini sebagai wujud kebersamaan di tengah kemajemukan masyarakat Tabalong," katanya. Ungkapan tersebut disampaikan pada Hari Jadi Emas ke 50 Kabupaten Tabalong di halaman Pendopo Bersinar Pembataan (Radar Banjarmasin, 2015).

\section{PERMASALAHAN}

Bagaimana rancangan Pusat Industri Fashion Batik dan Sasirangan Khas
Tabalong yang dapat meningkatkan kreativitas pembuat batik dan sasirangan khas Tabalong dengan tujuan memperkenalkan, melatih, membuat dan memajang hasil kreasi?

\section{TINJAUAN PUSTAKA}

\section{A. Tinjauan Pusat Industri Fashion Batik dan Sasirangan Khas Tabalong}

Pengertian industri menurut Undang-Undang Tahun 1984 Nomor 5 tentang Perindustrian, industri adalah kegiatan ekonomi yang mengolah bahan mentah, bahan baku, barang setengah jadi, dan/atau barang jadi menjadi barang bernilai tinggi dari segi penggunaan serta penjualan. Menurut Badan Pusat Statistik pengertian industri yaitu sebuah gabungan unit usaha yang menjalankan kegiatan ekonomi bertujuan untuk menghasilkan barang atau jasa yang berlokasi di tempat tertentu serta memiliki catatan administrasi pribadi. Pengertian fashion secara umum yaitu sebuah gaya berpakaian yang sedang trend atau populer dalam masyarakat dan budaya tertentu.

Batik Tabalong adalah batik motif khas dari Kabupaten Tabalong, Kalimantan Selatan, batik ini memiliki motif khas yang mengkombinasikan ukiran khas Dayak, sasirangan Banjar dan langsat Tabalong dalam berbagai warna. Batik ini dikenalkan oleh Bupati Tabalong pada hari jadi Kabupaten Tabalong ke-50 pada tanggal 1 Desember 2015.

Hj. Syarifah Syifa sebagai ketua tim penggerak PKK Kabupaten Tabalong mengatakan setiap motif harus mengandung nilai filosofis, makna atau sejarah yang menggambarkan ciri khas Kabupaten Tabalong, agar nantinya motif batik khas Tabalong bisa dikenal lebih luas oleh masyarakat Tabalong. Batik ini awalnya tidak diproduksi di Kabupaten Tabalong, melainkan di luar daerah yaitu Kulon Progo, 
Yogyakarta. Dalam rangka mewujudkan batik khas Tabalong diproduksi di tanah Sarabakawa, Pemerintah Kabupaten Tabalong melalui Dinas Perindustrian, Perdagangan, Koperasi dan UMKM Kabupaten Tabalong mengirim peserta pelatihan untuk membuat batik di Kabupaten Kulon Progo, Yogyakarta. Saat ini Batik khas Tabalong sudah diproduksi di Tabalong dengan beberapa UMKM dan dipasarkan di beberapa tempat. Selain itu di Tabalong juga dilakukan pelatihan pembuatan kain batik Tabalong yang dilaksanakan di salah satu UMKM pembuatan batik Tabalong.

Cara pembuatan batik ini ada dua, yaitu dengan ditulis (Batik Tulis) dan dengan di cap (Batik Cap).

\section{Batik Tulis}

Dimulai dari kain polos yang bernama kain Muri yang diberi pola dengan menggambar pola menggunakan pensil dan cetakan, lalu digambar menggunakan lilin dan canting, lalu siapkan pewarna tekstil ke dalam baskom dan beri air, celupkan kain tersebut ke dalam larutan berisi pewarna lalu diamkan beberapa saat, angkat kain tersebut dan jemur atau diangin-anginkan.

\section{Batik Cap}

Batik cap merupakan teknik menghias kain dengan corak batik menggunakan canting cap, dalam canting cap tersebut sudah tercetak motif batik tertentu. Canting cap biasanya terbuat dari tembaga, teknik ini biasanya digunakan oleh industri batik besar yang menuntut produktivitas tinggi. Kain polos di cap menggunakan alat seperti cetakan yang sudah berpola dan dicelupkan pada lilin, proses ini termasuk cepat karena si pembuat hanya perlu mencap pola pada kain polos dan selesai, lalu kain yang sudah bergambar dicelupkan pada larutan pewarna di dalam baskom dan dijemur.

Sasirangan Tabalong adalah sasirangan yang memiliki motif khas yaitu buah langsat dan Monumen Tanjung Puri atau yang dikenal dengan Tugu Obor. Sasirangan ini mengadaptasi dari beberapa motif Sasirangan konvensional yang dikombinasikan dengan motif langsat maupun obor. Sama halnya seperti Sasirangan di seluruh Kalimantan Selatan, cara pembuatan kain sasirangan ini tidak berbeda, yaitu dibuat dengan teknik tusuk jelujur. Cara membuat kain sasirangan yaitu dengan membuat pola, menjahit, menyisit, dan mencelupkan kain ke pewarna lalu diangin-anginkan.

\section{B. Tinjauan Arsitektural}

\section{Tinjauan Pameran}

Pameran merupakan kegiatan mempromosikan suatu produk oleh suatu produsen, kelompok, organisasi atau perkumpulan tertentu melalui tampilan display produk kepada calon relasi dan pembeli. Macam-macam pameran yaitu: show, exhibition, expo, fair, bazaar, pekan raya dan pasar murah.

2. Tinjauan Display

Display adalah suatu alat dan cara untuk menata produk barang oleh perusahaan tertentu dengan tujuan menarik perhatian konsumen.

\section{Tinjauan Kreativitas}

Kreativitas dijabarkan ke dalam empat jenis dimensi sebagai Four P's Creativity, yaitu Person, Proses, Press dan Product yang didefinisikan sebagai berikut:

Definisi kreativitas person adalah kreativitas yang berfokus pada individu yang disebut kreatif. Kreativitas merupakan kemampuan yang ada dalam diri seseorang (Guilford, 1950). Tindakan kreatif muncul dari keunikan serta kepribadian seseorang yang berinteraksi dengan lingkungannya (Hulbeck, 1945 dalam Munandar, 1999).

Definisi kreativitas process adalah kreativitas yang berfokus pada proses berpikir dan bekerja hingga mendapatkan ide-ide unik dan kreatif (Munandar, 1977 dalam Reni Akbar-Hawadi dkk, 2001).

Definisi kreativitas press, yaitu dorongan internal berupa keinginan diri sendiri untuk menciptakan atau bekerja 
secara kreatif, atau dorongan secara eksternal dari lingkungan sosial dan psikologis (Simpson (1982) dalam S. C. U. Munandar 1999). Definisi kreativitas product yaitu upaya untuk menghasilkan kreativitas yang berfokus pada produk kreatif yang dihasilkan oleh individu baik sesuatu yang baru atau sebuah penggabungan yang telah di inovasi (Baron, 1969).

\section{METODE}

Metode perancangan yang digunakan untuk Pusat Industri Fashion Batik dan Sasirangan Khas Tabalong adalah metode Architectural Programming oleh Donna $P$. Duerk. Metode tersebut dipilih karena cocok dengan permasalahan yang diangkat yaitu kreativitas. Metode Architectural Programming memiliki fokus pada dua area, yaitu Existing State berisi data-data fakta, serta Future State berisi penyusunan isu, tujuan, performance requirement, dan konsep.

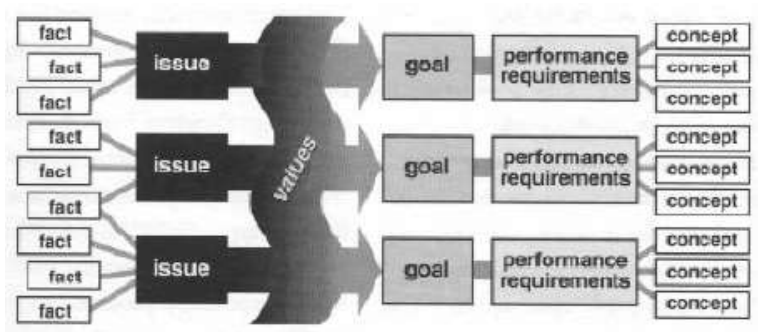

Gambar 1 Diagram skematik metode perancangan

Sumber:

http://www. arch.ttu.edu/courses/2014/fall/4341/Pr ogramming.htm diakses 26 Desember 2018

\section{PEMBAHASAN}

\section{A. Konsep Programming}

Batik dan Sasirangan khas Tabalong memiliki motif khas yang tercipta dari perpaduan budaya yang berbeda yaitu motif dari suku Dayak dan suku Banjar, selain itu untuk menghasilkan suatu inovasi motif dan pakaian jadi yang baru dibutuhkan suatu kreativitas dengan konsep kreativitas 4P (person, process, press, product) maka dari itu konsep yang dipilih adalah "Cultural to Creativity".

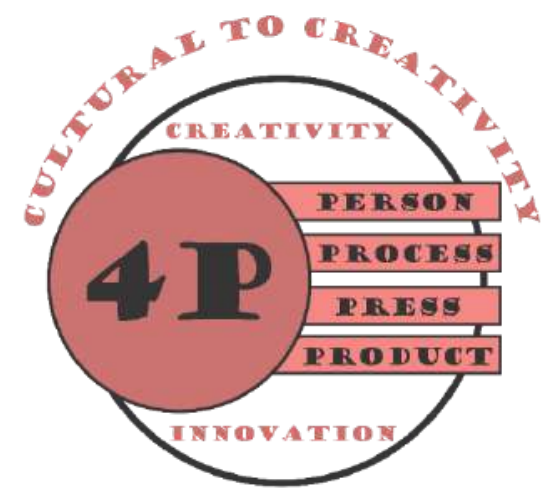

Gambar 2 Konsep Programming Sumber: Penulis, 2019

Kreativitas diartikan dalam 4P yaitu Person, Process, Press, Product yang saling terkait, yaitu person kreatif yang melibatkan diri dalam process kreatif, dan dengan press dari lingkungan serta diri sendiri sehingga menghasilkan produk yang kreatif (Rhodes).

\section{B. Konsep Rancangan}

1. Konsep Massa Bangunan

Bangunan dibuat menjadi 4 massa utama dan 2 massa pendukung, yang mana terdiri dari Exhibition Hall, Galeri, Gedung pembuatan dan Management Office. Parkir diletakkan di area depan dan samping bangunan sesuai dengan jalur sirkulasi kendaraan. Pada tengah tapak diletakkan ruang terbuka hijau yang menjadi penghubung antar bangunan. Pada bagian depan diletakkan bangunan yang dapat menunjang minat pengunjung, seperti galeri yang berisi toko dan ruang pengenalan dan Exhibition Hall. Area produksi seperti ruang pembuatan kain, area untuk management office dan area mekanikal elektrikal diletakkan di bagian samping serta belakang. 
Penyusunan tata massa ini didasari oleh alur aktivitas dari pembatik, pengelola dan pengunjung.

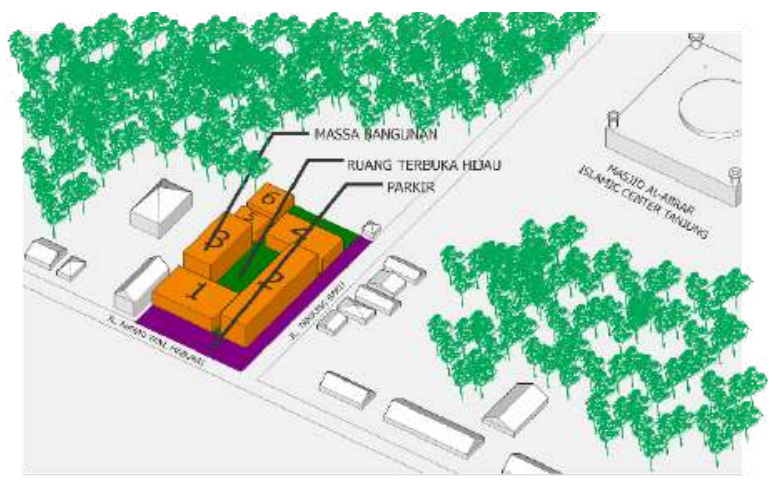

Gambar 3 Konsep Massa Bangunan Sumber: Penulis, 2019

\section{Konsep Kultural}

Konsep cultural yang diambil adalah Pertama, konsep bentuk bangunan dan konsep finishing material pada eksterior bangunan. Konsep bentuk bangunan mengambil bentuk dari Talawang (perisai suku Dayak). Kedua, konsep finishing material bangunan. Konsep ini adalah konsep material apa saja yang akan digunakan untuk bangunan, dan dimana peletakan solid dan void pada bangunan, seperti contohnya menggunakan material kaca atau Tempered Glass pada bagian void.

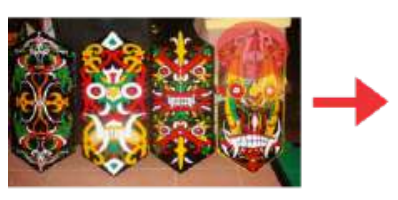

TALAWANG

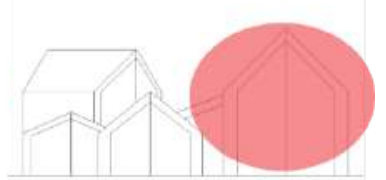

TAMPAK BANGUNAN
Gambar 4 Konsep Bentuk Bangunan Sumber: Penulis, 2019

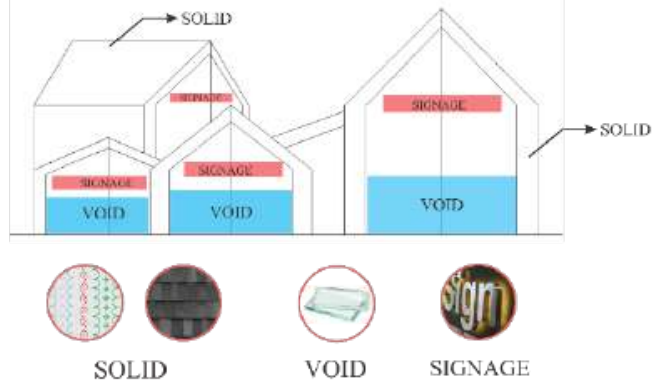

Gambar 5 Konsep Finishing Material Bangunan Sumber: Penulis, 2019

\section{Konsep Creativity (Person)}

1. Konsep Ruang Istirahat

Konsep person ini untuk meningkatkan kreativitas individu, Pada dinding ruang istirahat diterapkan gambar tentang Kabupaten Tabalong, yang diharapkan pada saat istirahat para pembuat kain batik dan sasirangan ini dapat terinspirasi. Karena menurut $\mathrm{Hj}$. Syarifah Syifa sebagai ketua tim penggerak PKK Kabupaten Tabalong mengatakan bahwa setiap motif harus mengandung nilai filosofis, makna atau sejarah yang menggambarkan ciri khas Kabupaten Tabalong.

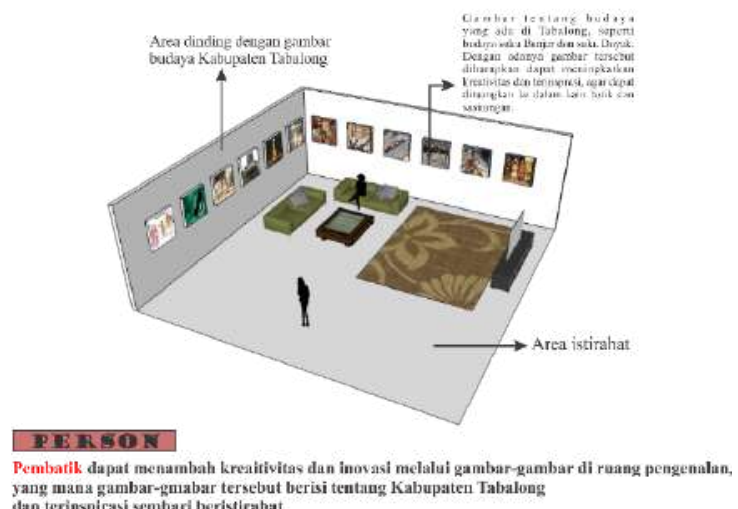

Gambar 6 Konsep Ruang Istirahat Sumber: Penulis, 2019 


\section{Konsep Display Ruang Pengenalan}

Untuk pengunjung agar mengetahui seperti apa batik dan sasirangan khas Tabalong, maka konsep yang dipakai adalah peletakan teori pada ruang pengenalan secara berurutan, selain itu display dibuat semenarik mungkin agar tidak monoton, dengan bentuk display yang beragam, mulai dari window display (sistem vitrin), panel dan terbuka.

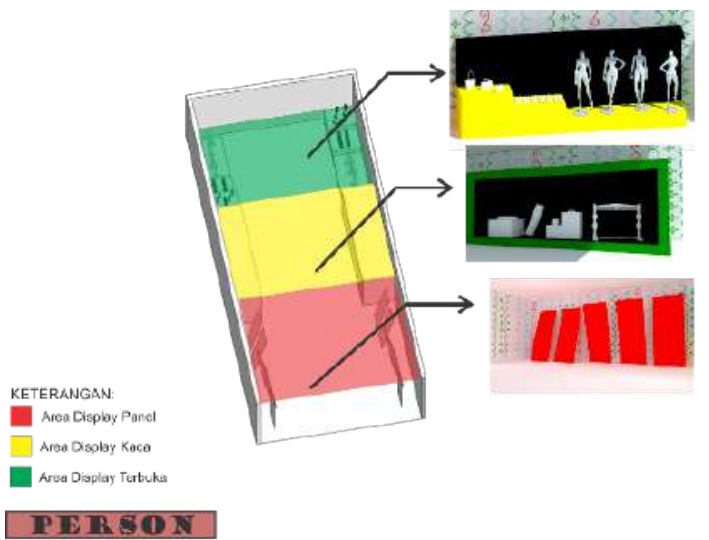

Pengunjung dapat memahami dengan baik karena pada ruang pengenalan disediakan berbagai macam display yang dibagi menjadi tiga bagian, yang pertama berisi cerita berbentuk tulisan dan foto, yang kedua berisi peralatan dan bahan, yang terakhir berisi produk hasil karya

Gambar 7 Konsep Display Ruang Pengenalan Sumber: Penulis, 2019

Area display panel berisi pengenalan dengan teori tertulis dan gambar (budaya suku Banjar dan suku Dayak) serta pengenalan tentang motif batik dan sasirangan khas Tabalong. Area display kaca berisi pengenalan peralatan dan bahan untuk membuat kain batik dan sasirangan khas Tabalong Area display terbuka memajang hasil karya produk fashion dari kain sampai pakaian jadi seperti baju, tas, sepatu, sandal, dan lain-lain.

\section{Konsep Plafond}

Pada konsep plafon juga diterapkan bentukan dari motif kain sasirangan, bentuk yang digunakan untuk plafon adalah motif gelombang. Motif gelombang dipilih karena makna yang terkandung, motif gelombang memiliki artian mengarungi gelombang kehidupan, yang mana saat berada di Pusat Industri ini pengunjung dibawa untuk terus mengarungi (berjalan-jalan) di Pusat Industri.

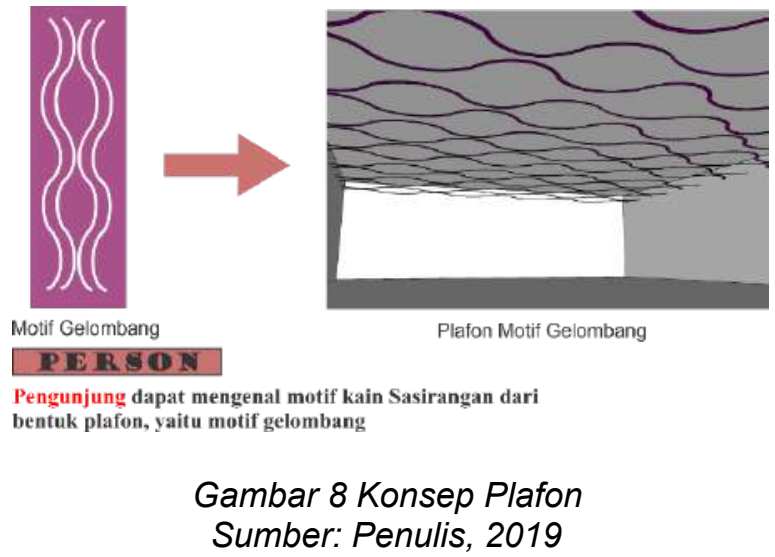

4. Konsep Pintu Jendela

Konsep pintu dan jendela juga menggunakan bentuk dari motif kain sasirangan, yaitu motif daun katu untuk pintu dan gagatas untuk jendela.

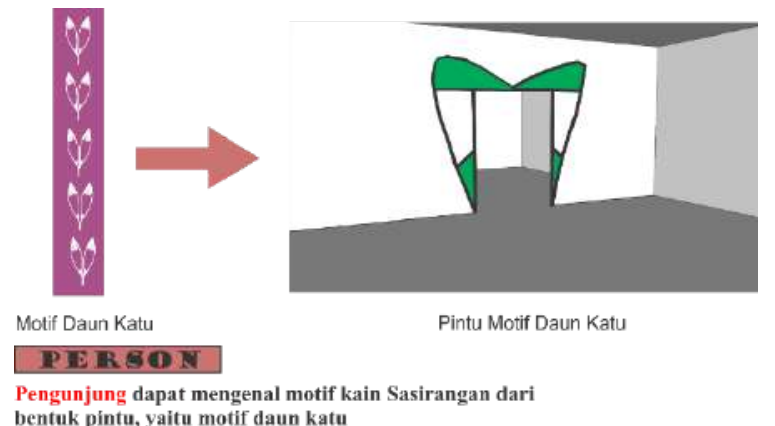

Gambar 9 Konsep Pintu

Sumber: Penulis, 2019

Pintu yang berbentuk motif daun katu adalah pintu yang menghubungkan antar ruang, bukan pintu utama yang menuju ke dalam bangunan. Motif daun katu dipilih karena makna dari motif ini adalah daun katu sering ditanam di depan rumah orang Banjar untuk melancarkan ASI, jadi diartikan 
pada pintu adalah dapat menumbuhkan kepercayaan diri saat melewati pintu untuk sesuatu yang baru.

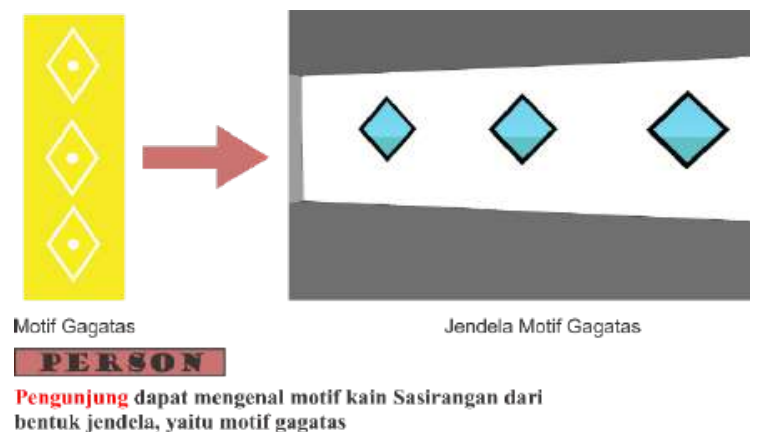

Gambar 10 Konsep Jendela

Sumber: Penulis, 2019

Untuk motif gagatas pada jendela dipilih karena memiliki artian bungas (cantik), tidak akan bosan dipandang, jadi motif ini dijadikan jendela agar orang luar tertarik untuk memandang jendela dan penasaran dengan aktivitas yang ada di Pusat Industri Fashion Batik dan Sasirangan khas Tabalong. Semua bentuk yang dipilih adalah motif dari kain sasirangan, yang mana pengunjung dapat mengenal motif-motif dari kain sasirangan.

\section{Konsep Warna}

Konsep warna yang diaplikasikan merupakan warna-warna yang terdapat pada kain sasirangan, yang mana warna pada kain sasirangan memiliki kepercayaan dapat menyembuhkan penyakit. Warna-warna ini diaplikasikan ke berbagai elemen seperti bangunan serta furniture.

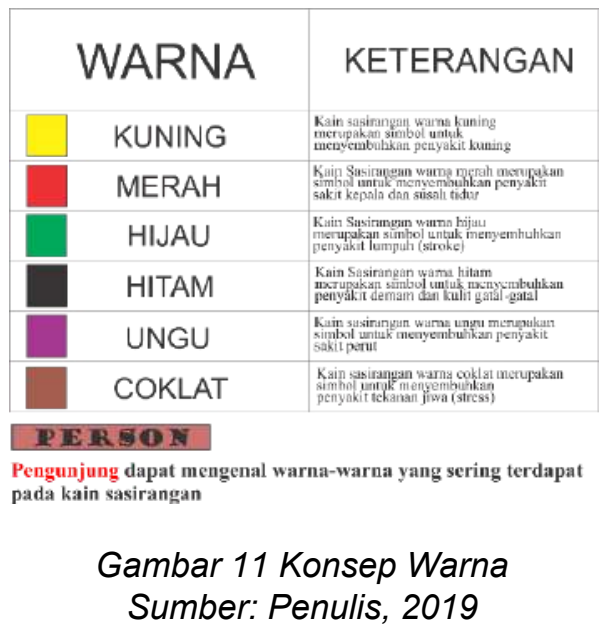

\section{Konsep Creativity (Process)}

1. Konsep Ruang Pembuatan

Proses pembuatan adalah hal yang sangat penting dalam pusat industri, maka dari itu konsep process ini diterapkan pada gedung produksi, yang mana pengunjung dapat melihat proses pembuatan kain batik dan sasirangan.

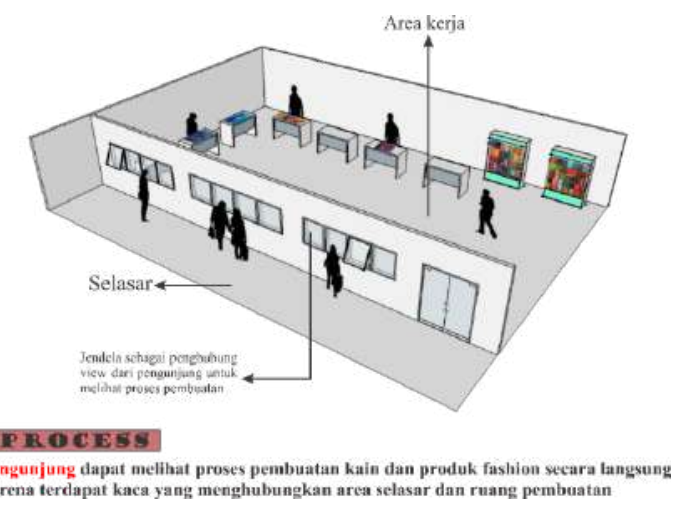

Gambar 12 Konsep Ruang Pembuatan Sumber: Penulis, 2019

2. Konsep Sirkulasi Ruang Pengenalan Konsep sirkulasi linier diterapkan pada galeri dan gedung produksi, karena sirkulasi ini lebih terarah, teratur, dan pengunjung akan mudah memahami alur dari display pada ruang pengenalan dan alur pembuatan pada gedung produksi. Sehingga pengunjung diarahkan untuk 
melihat display sesuai alur sirkulasi yang telah ada.

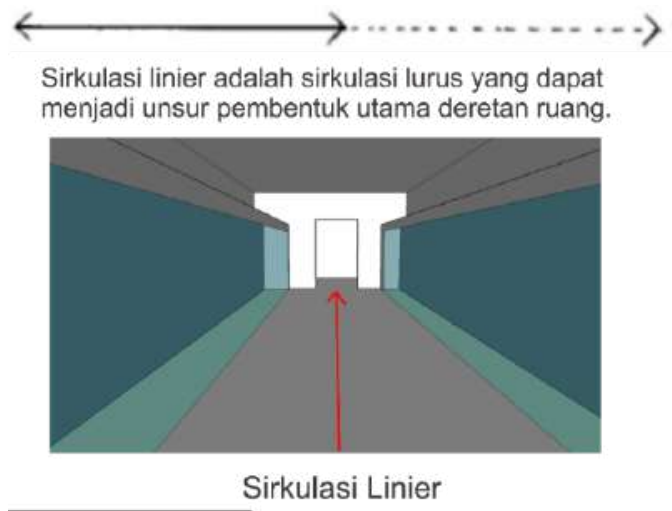

\section{PI (1) C ES}

Pengunjung dapat dengan mudah memahami proses terciptanya kain batik dan sasirangan khas Tabalong hingga menjadi produk fashion, karena sirkulasi linier yang teratur

\section{Gambar 13 Konsep Sirkulasi Linier}

Sumber: Penulis, 2019

\section{E. Konsep Creativity (Press)}

1. Konsep Ruang Kerja Bersama

Konsep press diterapkan pada ruang pembuatan yang bekerja bersama-sama dalam satu ruangan, karena dengan adanya ruang bersama maka akan ada dorongan dari eksternal atau lingkungan luar dan orang lain untuk menciptakan kreativitas dan inovasi pada kain batik dan sasirangan.

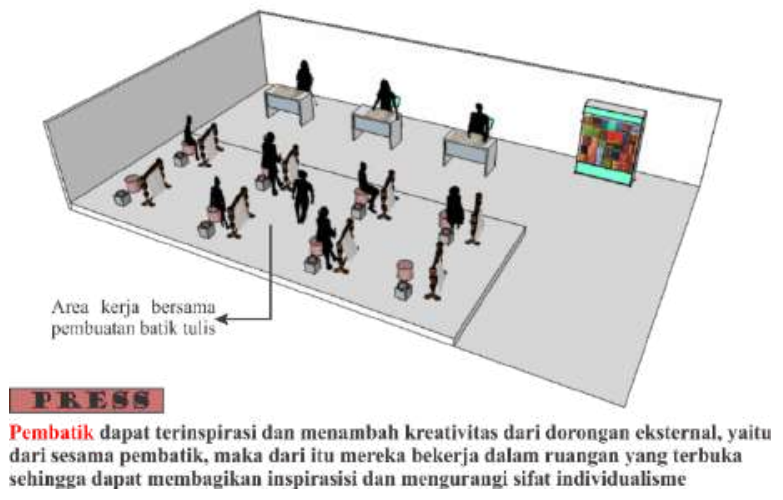

Gambar 14 Konsep Ruang Kerja Bersama Sumber: Penulis, 2019

\section{Konsep Ruang Pelatihan}

Konsep ruang pelatihan ini dibuat agar para peserta pelatihan dapat dengan mudah mempelajari proses pembuatan kain batik dan sasirangan begitu juga dengan proses pembuatan kain menjadi produk fashion. Pada ruang pelatihan terdapat dua area yaitu area pelatihan teori dan area pelatihan praktik.

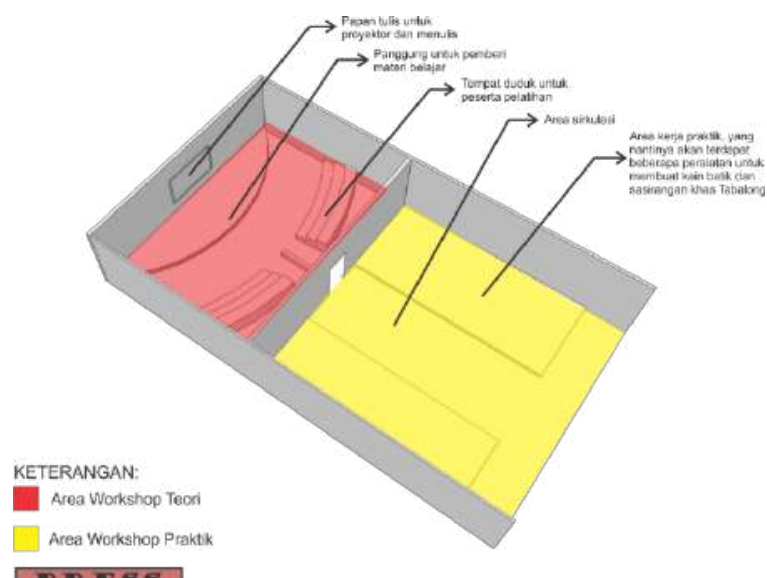

Pengunjung/peserta pelatihan belajar dan lebih terlatih dengan Pengunjung/peserta pelatihan belajar dan lebih terlatih dengan
memahami teori serta dengan secara langsung merasakan pengalaman membuat kain batik dan sasirangan khas Tabalong secara praktik

\section{Gambar 15 Konsep Ruang Pelatihan} Sumber: Penulis, 2019

\section{F. Konsep Creativity (Product)}

1. Konsep Ruang Exhibition Hall

Produk merupakan hasil dari sebuah kreativitas dan inovasi, yang mana penerapan ruang untuk konsep product adalah ruangan yang dapat menampilkan dan mempromosikan produk seperti contohnya adalah Exhibition Hall. 


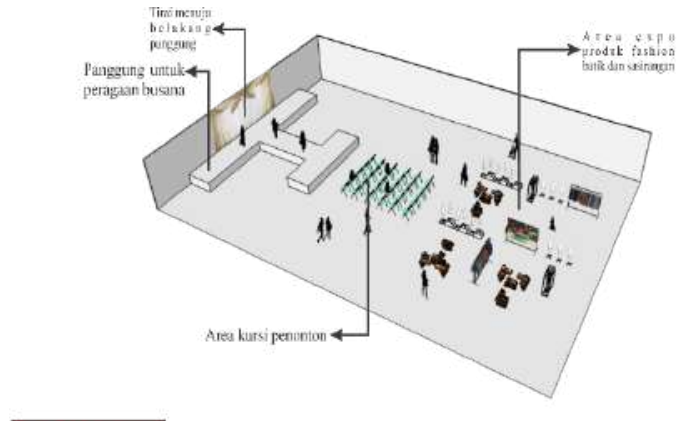

PKODECT

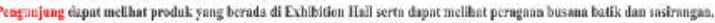

\section{Gambar 16 Konsep Exhibition Hall}

Sumber: Penulis, 2019

Untuk pameran yang dilaksanakan di dalam Exhibition Hall, adalah pameran temporer yang hanya berlangsung minimal 10 hari dan maksimal 1 bulan, jadi untuk konsep pameran disesuaikan dengan tema yang diusung saat itu.

\section{Konsep Sirkulasi Exhibition Hall}

Konsep sirkulasi network diterapkan pada exhibition hall, karena pada saat pameran pengunjung bebas untuk berkeliling untuk melihat-lihat.

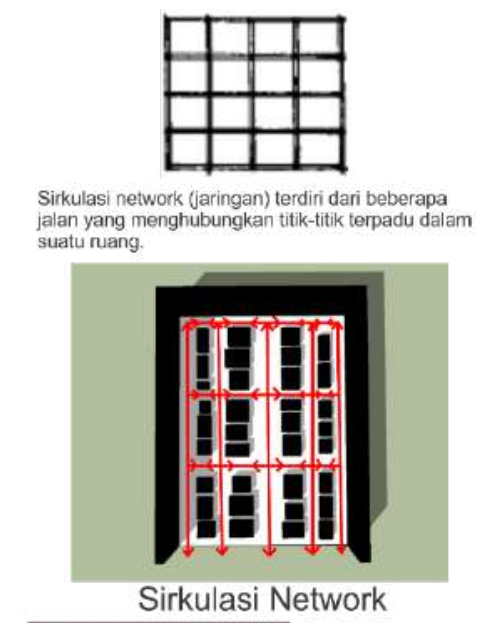

\section{PI D D UCT}

Pembatik/pengelola dapat menyusun display produk dengan mudah sesuai dengan sirkulasi, karena pameran yang dilaksanakan adalah paemran temporer yang mana harus menyesuaikan produk

dengan tema yang diusung

Pengunjung bebas untuk berjalan mengelilingi pameran sesuai keinginan mereka, karena pameran sudah disusun dengan sedemikian rupa untuk terciptanya sirkulasi network

Gambar 17 Konsep Sirkulasi Network Sumber: Penulis, 2019

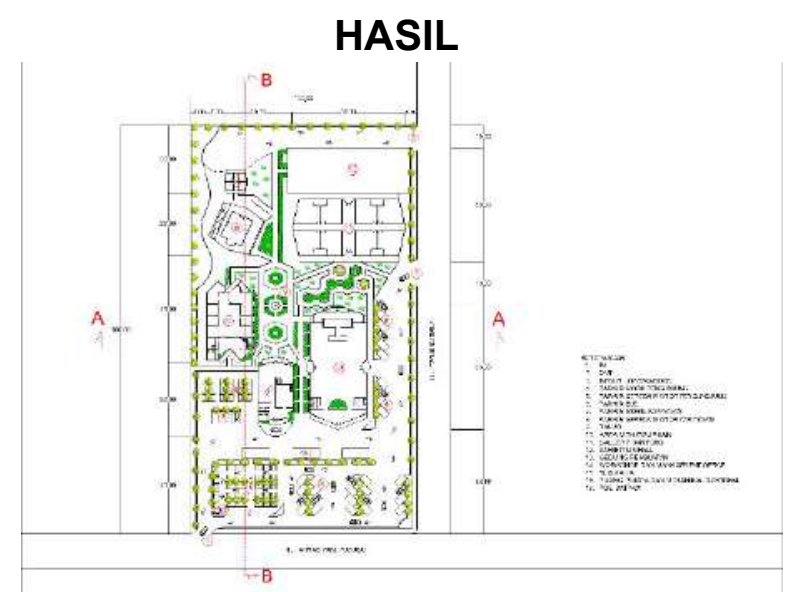

Rencana Tapak

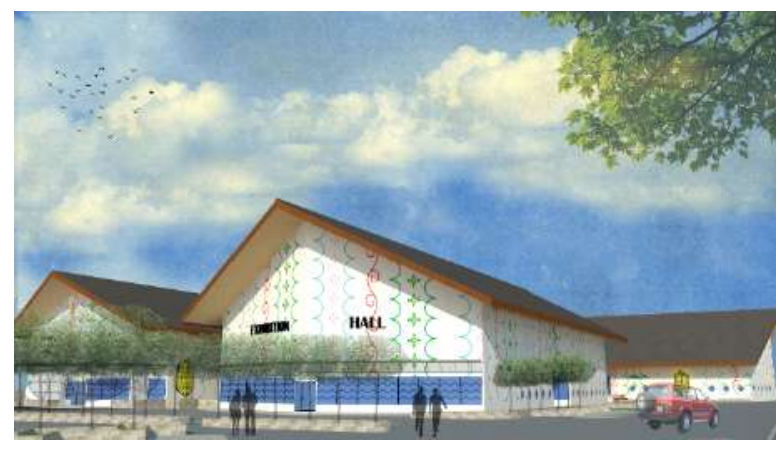

Perspektif Bangunan 


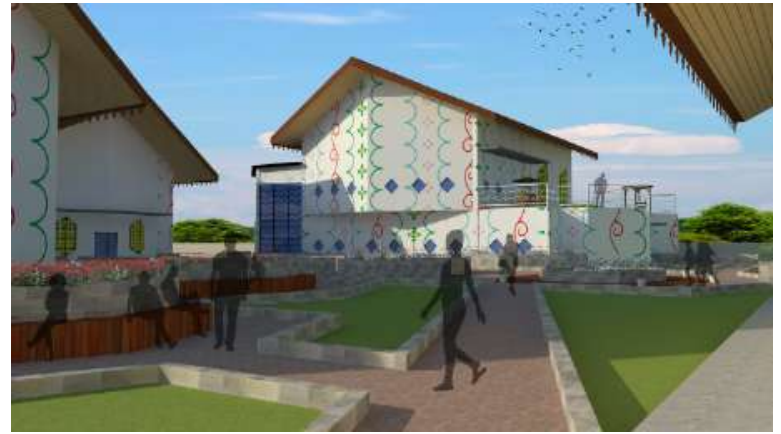

Perspektif Taman

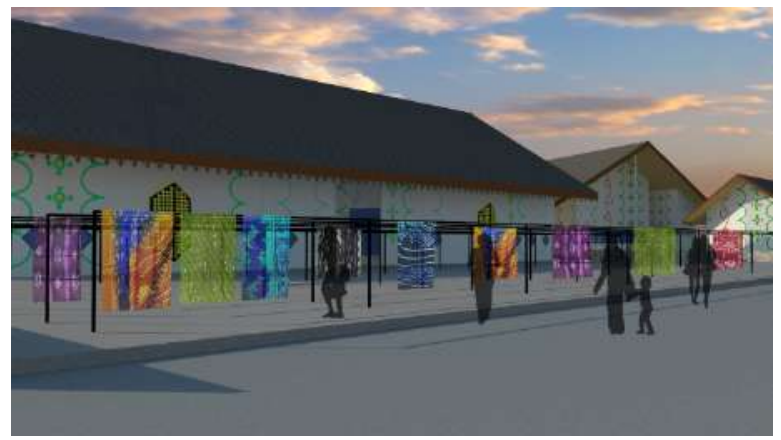

\section{Perspektif Area Jemur}

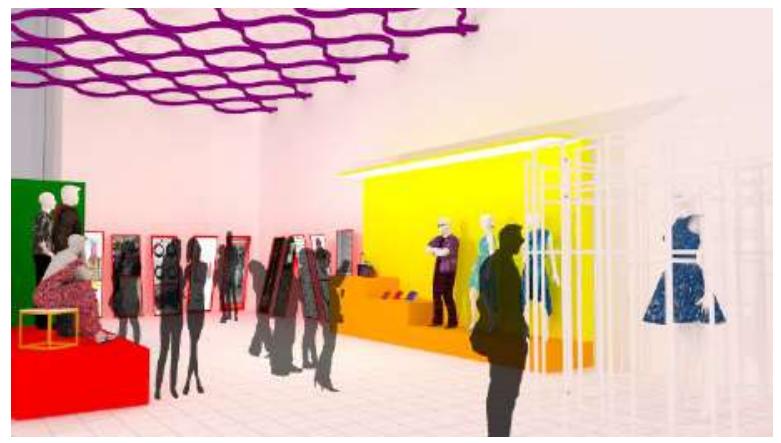

Perspektif Gallery

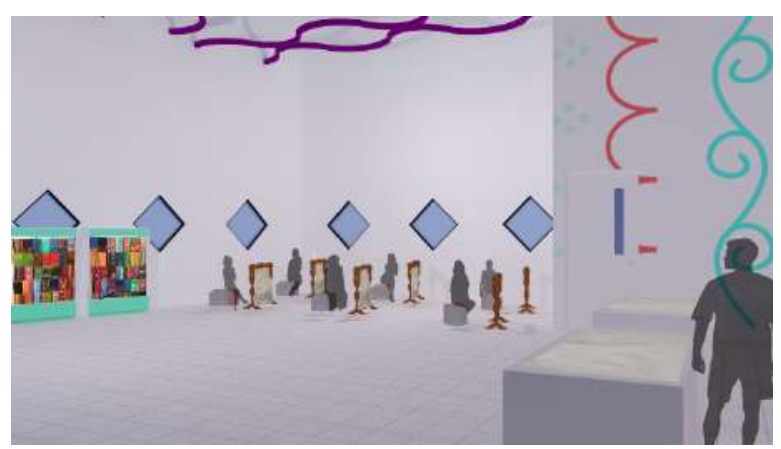

Perspektif Ruang Pembuatan Kain Batik

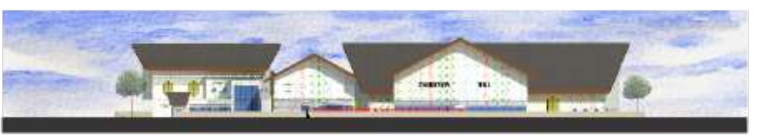

\section{Tampak Depan}

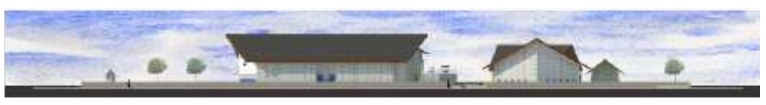

Tampak Samping Kanan

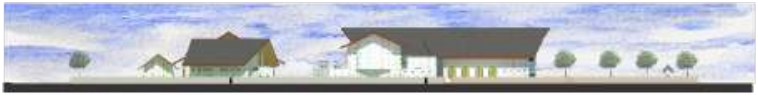

Tampak Samping Kiri

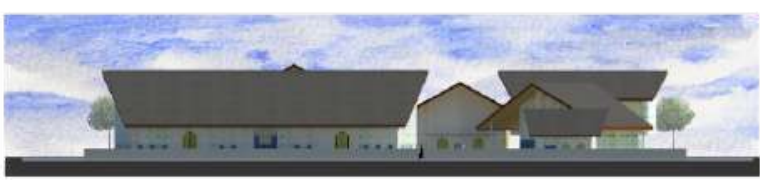

Tampak Belakang

\section{KESIMPULAN}

Perancangan Pusat Industri Fashion Batik dan Sasirangan Khas Tabalong bertujuan untuk memfasilitasi para pembatik kain Batik dan Sasirangan yang ada di Tabalong serta masyarakat maupun wisatawan untuk mengenal dan belajar pembuatan kain maupun produk jadi dari kain Batik dan Sasirangan Khas Tabalong, yang mana didalamnya ada tempat untuk memperkenalkan, melatih, membuat dan memajang hasil kreasi produk fashion.

Pusat Industri Fashion Batik dan Sasirangan Khas Tabalong menggunakan konsep Cultural to Creativity sebagai konsep serta metode programming sebagai cara menyelesaikan permasalahan. Konsep Cultural to Creativity dipilih karena dirasa cocok untuk permasalahan yang membutuhkan kreativitas dan inovasi dalam membuat kain batik dan sasirangan yang tercipta dari perpaduan budaya yang berbeda yaitu motif dari suku Dayak dan suku Banjar. Konsep ini lalu diintegrasikan kepada konsep industri kreatif yaitu 4P (person, process, press, product) sebagai 
penguat dalam konsep Cultural to Creativity tersebut.

Konsep budaya pada bangunan ini diaplikasikan pada bentuk bangunan yang mana terinspirasi dari bentuk Talawang suku Dayak, selain itu pada finishing dinding bangunan menggunakan gravity dari kain Sasirangan. Untuk konsep 4P diterapkan pada ruangan yang membutuhkan adanya kreativitas dan inovasi bagi para perajin dalam membuat produk fashion yang menarik bagi wisatawan. Bangunan dari Pusat Industri Fashion Batik dan Sasirangan Khas Tabalong terdiri dari beberapa massa bangunan yaitu galeri sebagai tempat pengenalan maupun untuk memajang hasil karya dan menjualnya, Exhibition Hall sebagai tempat peragaan busana maupun expo, gedung pembuatan, kantor untuk pengelola dan fasilitas penunjang

\section{DAFTAR PUSTAKA}

(2012). Badan Pusat Statistik
Kabupaten Tabalong
(2016). Journal of Innovation and
Entrepreneurship
(2018). Kabupaten Tabalong Dalam
Angka
De Chiara, Panero \& Zelnik, 1992, Time
Saver Standards for Interior Design
and Space Planning
Fachriana, Sitta Annisa. (2016). Galeri
Sasirangan di Kampung Sasirangan
[Skripsi]. Banjarbaru (ID): Universitas
Lambung Mangkurat.
Herlinda, Vania. (2018). Creative Hub
Banjarmasin [Skripsi]. Banjarbaru (ID):
Universitas Lambung Mangkurat.
Neufert, E. 1996. Data Arsitek Jilid 1.
Jakarta: Erlangga
Neufert, E. 2002. Data Arsitek Jilid 2.
Jakarta: Erlangga
Puerk, Donna, 1993, Architectural
Programming:
Management for Design

Sachari, Agus, 1995, Laporan Penelitian Diversifikasi Desain Produk Pasirjambu Ciwidey Jawa Barat, LPPM ITB, hal. 5.

Seman, Syamsiar, Drs. H. M. 2013. Sasirangan Kain Khas Banjar. Cetakan Kesembilan.Lembaga Pengkajian dan Pelestarian Budaya Banjar Kalimantan Selatan 